hunting and marking whales. The pack ice was encountered on December 3 when seven days out from Cape Town. Whales had been found on December 1 and marking began on that date.

The R.R.S. William Scoresby is an oil-burning steam vessel, and arrangements had been made for supplies of fuel oil from the whaling factory ships operating in the neighbourhood. On reaching the pack ice the vessel turned eastwards along its edge, and a few days later ships of the whaling fleet were heard in wireless communication with each other. When fuel oil was required, the vessel was enabled to find the desired factory ship by wireless bearings. She went alongside the factory ships in the same manner as the catchers go alongside for fuel-that is, with a floating whale carcase between the two ships to act as a fender. This manœuvre was carried out, in the open ocean, on eight occasions.

At the beginning of the season, the majority of the whaling fleet was found to be operating in the neighbourhood of Queen Mary Land, and marking was carried out in this area until the middle of January. During this period, which was largely spent near the edge of the pack ice or inside it, the work was hampered by poor visibility, much snow and fog, but on several occasions when the weather was good, numbers of Humpback and Fin whales were met and marked. Half way through January, a return westwards to the whaling grounds of Enderby Land was made, again skirting the pack ice which was now lying considerably farther south. Off Enderby Land, work was carried on in the open ocean and the pack ice was not again encounterece during the remainder of the season. From this time until almost the end of the season, the weather was good and both Blue and Fin whales were usually to be found, sometimes in large numbers. Fin whales are to be met with at this time of the year in bodies numbering as many as fifty to a hundred and, on occasions, two such bodies were found in the course of a single day. When this occurred it was possible to mark between forty and fifty in the long daylight hours.

One month was spent in the waters off Enderby Land, and in March the ship moved westwards to the south of Bouvet Island. In the middle of March course was laid for the Cape, which was reached on March 29 after 122 days at sea without sighting land of any kind. During this time between seven and eight hundred whales-Blue, Fin, Humpback and Sperm-had been marked.

When opportunity offered, during bad weather or dark hours, water and plankton samples were taken and, for a few days in February, when in wireless communication with the R.R.S. Discovery II, the William Scoresby was able to co-operate to a small extent in her programme of hydrographic and plankton research.

In the months of December and January of this season, whale-marking was also carried out in the waters around South Georgia by Mr. A. H. Laurie, and several hundred Fin and Blue whales were marked in this area.

A number of whales marked during this commission have already been captured by the whalers, and the marks, together with the required data, returned to the Discovery Committee. Marks from Blue, Fin and Humpback whales have thus been recovered after periods varying from a few hours to three and a half months; and the distances traversed range from a few miles to a thousand miles. The data thus obtained are extremely instructive in showing the trend of movement of the whale stock on these grounds during the course of the season, but more valuable results are to be expected from marks returned during next whaling season.

\title{
National Food Policy
}

\section{British Association Discussion on Economics of Diet}

$\mathrm{T}$ $\mathrm{HE}$ discussion on the economics of diet before Sections F and I (Economics and Physiology) at the recent Norwich meeting of the British Association, and the resolution on nutrition at the present assembly of the League of Nations has emphasised the interdependence of problems of public health, agriculture and economics. This interdependence has become evident in the last few years of trade depression when attempts, which are not very successful, are being made to deal with the problems of these subjects separately.
It is now being realised that they must be considered together in the light of the international position.

The world economic crisis paralysed international trade in foodstuffs as well as in other commodities. But agricultural production cannot be cut down so quickly as industrial factory production. Consequently stores of foodstuffs accumulated and prices fell.

The first reaction was an attempt to control production, limit imports and regulate marketing 
with the object of raising prices. It was thought that when wholesale prices of foodstuffs rose, the purchasing power of primary producers for industrial commodities would be increased and general prosperity would return with an all-round rise in prices.

A different view is that low prices for agricultural products are the result rather than the cause of trade depression. Under-consumption, due to low purchasing power of the people in the industrial centres where depression is worse than in agriculture, is a more potent factor than overproduction. Hence raising prices by reducing production and regulating the markets will lead to a further lowering of consumption, with the 'glut' appearing at a still lower level of consumption, a still further restriction in trade, and in addition, an increase in malnutrition due to a worsening of the diet of the poorer classes of the community. Those who approach the problem from this angle wish to find a solution of our problems in increased consumption rather than in controlled production.

The crux of the difficulty is how to initiate the desired increased consumption. One of the speakers at the British Association suggested that a beginning should be made with food. The present Agricultural Marketing Boards should be replaced by public utility companies which would run the processing centres; for example, centralised slaughter-houses, bacon factories, wholesale milk depots, through which products must pass from the farm to the consumer. These Boards would buy from the farmer and sell to the distributing trade. The gulf between what the farmer would get and what the consumer is asked to pay would be bridged by a direct subsidy from the State, paid to these Boards.

There would be no control of retail prices, because the services of distribution vary so widely in different classes. But the Boards, either themselves or by arrangement with distributors, would make the staple foodstuffs available at a price within the reach of the poorest. They would be available without tickets and irrespective of class, to all who would be willing to collect food from the depots or shops, and so save the cost of distribution which, in the case of some foodstuffs, for example, milk, is about half the retail price.

With the subsidy and this saving in the cost of distribution for those who care to take advantage of it, a diet adequate for health would be within the reach of the poorest. It was suggested that the result would be a reduction in preventible disease which, within a reasonable time, would effect savings in the cost of public health services which would go far to offset the cost of subsidising increased consumption. In addition to ultimate savings arising from improvement in health, there would be an immediate saving in the cost of complicated public health measures such as free meals and cheap milk for school children, and the issue of dried milk free or at reduced prices at child welfare centres. These measures with their taint of pauperism would be no longer necessary.

The results of a preliminary inquiry seemed to indicate that there may be as many as twenty million of the population whose health would be improved by an increased consumption of the more expensive foodstuffs such as fruit, vegetables, milk and animal products, and an examination of family food budgets and family incomes showed that price was the limiting factor for the consumption of these. If consumption were increased to a level at which every member of the community had a diet adequate for health, there would be room for a considerable expansion of agriculture in Great Britain without decreasing imports.

To initiate a national food policy on these lines, however, requires a Government subsidy, and subsidies are unpopular. It is argued, however, that the subsidy, in addition to making agriculture remunerative, would irrigate the field of internal trade, stimulate industries, and flow back again to the Treasury in increased income tax and other receipts.

On the same day as the discussion at Norwich, twelve countries, including Great Britain, France and Italy, submitted to the Assembly of the League of Nations a resolution stating that "the relationship of nutrition to the health of the people has become a social and economic problem of widely accepted significance", and that "this subject has an important bearing on world agricultural problems". The League has approved an inquiry into the whole question.

The discussion at the British Association and at the League of Nations has aroused sufficient interest to ensure that there will be a fuller inquiry. It is probable that we may be working towards a national food policy into which both agriculture and public health interests can be fitted and reconciled. But as one of the speakers at the British Association urged, we need far more information than is available before a food policy can be elaborated. It is in the public interest that such an inquiry should be instituted to ascertain :

What is the amount of increased consumption required to provide an adequate diet for every member of the community?

To what extent can health be improved by increased consumption of certain foodstuffs? 
What effect would increased consumption have on British agriculture and on trade ?

What economic and financial measures are required to initiate and promote increased consumption?

There is obviously a wide field of inquiry in which different Government departments should co-operate. A halt should be called to planning according to preconceived theories. We need far more information than is available before any more marketing schemes affecting the food supply of the country are brought into being.

\section{Obituary}

\section{Sir John McLennan, K.B.E., F.R.S.}

$\mathrm{T}$ THE great Exhibition, held in 1851, resulted in a large profit which was well invested, and the income has for many years been awarded as scholarships to research students. The results prove that it was one of the best investments ever made. John Cunningham McLennan, among many other men ultimately distinguished in science, received such an award, and it enabled him to join the Cavendish Laboratory at Cambridge from his home in Ontario after his graduation at the University of Toronto. Under the guidance of Sir J. J. Thomson, the Cavendish was enjoying a burst of discovery in connexion with the electron and the ionisation of gases. Young McLennan quickly caught fire, and on his return to Toronto as a demonstrator in physics, at the age of thirty-two, he published a paper in the Transactions of the Royal Society $(195,1899)$ in which he proved that the ionisation of gases due to electrons in motion was similar in type to that due to Röntgen rays or the radiations from uranium.

At the same time that Rutherford and H. L. Cooke at MeGill were discovering the penetrating radiation, supposedly and mainly from the radioactive substances in the ground, McLennan and E. F. Burton were finding, independently, similar results at Toronto. The later expansion of this subject into cosmic radiation was not then suspected. McLennan also carried out many experiments on the 'natural ionisation' in closed vessels, tracing the effects to minute quantities of radioactive materials, such as polonium in the walls, or radon in the enclosed air. By exposing sealed ionisation electroscopes over the ice on Lake Ontario, he definitely proved that the penetrating radiation over land was greater than over water, and this showed that a large part of the penetrating radiation came from the radium which Lord Rayleigh proved to be widely distributed in small quantities throughout primary and secondary rocks and sediments.

With immense energy, McLennan worked with others to raise funds for building that great physical laboratory at the University of Toronto which now so happily bears his name. Moreover, he secured abundant equipment with excellent apparatus especially for spectroscopy. One of his early successes was the discovery of the single line spectra of zinc, cadmium and magnesium and the deduction of their ionisation potentials. This was a sequel to the work of Frank and Hertz, who had obtained the single line spectrum for mercury. Electrons projected with low voltages in a discharge tube will excite a single line, but at a higher critical voltage the usual many-lined spectra appear.

During the War, McLennan came to England and took an intensely active part in the research work of the Admiralty in connexion with the anti-submarine campaign. His view was that a professor was coequal in rank with an admiral, and he reported directly to the First Sea Lord. Thus, in certain magnetic work, he insisted on the speedy isolation of a submarine in a dock at Portsmouth with a view to a magnetic survey and the determination of its magnetic moment, hitherto an unknown quantity. At the same time, he organised the extraction of helium from natural gases near Calgary, and obtained a considerable quantity intended for airships and balloons, but actually used after the War for experimental purposes. During the greater part of 1919 he was scientific adviser to the Admiralty.

After the War, McLennan returned to Toronto and continued with enthusiasm and success his work on spectroscopy, for which he was awarded a Royal Medal of the Royal Society in 1927, and the following year he had the honour of giving the Bakerian Lecture to the Society on "The Aurora and its Spectrum". The brilliancy of the aurora is shown by the spectroscope to be due to nitrogen, and the lower limit of the height of the discharge has been proved by Størmer to be about eighty miles above the earth's surface. On any clear night it had been proved by Lord Rayleigh, Vegard and others that there is also present in the spectrum a notable green line (5377) the cause of which gave rise to much controversy. In the Bakerian Lecture (Proc. Roy. Soc., A, 120, 1928) MeLennan described how he and G. M. Shrum had proved in the laboratory that the green line was due to oxygen, suitably mixed with argon, which when in a metastable state, as Frank had shown in similar cases, is capable of transferring its energy to a different type of gas.

McLennan next determined with eharacteristic energy to instal at Toronto a eryogenic laboratory capable of liquefying air, hydrogen and helium. In this difficult undertaking he received advice and plans from Onnes at Loyden and financial support from the National Research Council of Canada, and 